\section{Restructuring gets underway}

\section{Munich}

IN a move that enraged researchers in the former East Germany, but created hope for change in an inflexible research structure in the west, the science council Wissenschaftsrat last week recommended drastic staff cuts and an entirely new structure at three research institutes in East Berlin that used to be attached to the East German Academy of Sciences.

The institutes are the Central Institutes for Molecular Biology (ZIMB), for Cancer Research and for Heart and Circulatory Research, which share a campus with two hospitals in Berlin-Buch.

At the same time, the council passed a milder judgment on the (much smaller) former academy institute for high-energy physics at Zeuthen, calling for a majority of the personnel to be maintained and the institute to be integrated into a related institute in the west.

The recommendations for Berlin-Buch and Zeuthen were among the first of many recommendations expected in next few months would put a radically new face on science in eastern Germany and improve the status of German science as a whole. But the council warned that to work its initiatives have to be backed up with money from both Bonn and the Länder (states).

\section{NIH in Berlin?}

If followed, the recommendation for Berlin-Buch could give Germany its first truly interdisciplinary research institution combining basic biology research with clinical research in the tradition of the US National Institutes of Health (NIH). Wissenschaftsrat called for at least half of the positions to be of limited duration and half of the money to come from research grants, in contrast to the inflexible staff and funding structure of most western German research institutions.

Insiders say that the proposal has only a small chance of succeeding in its present form. Wissenschaftsrat calls for the hospitals in Berlin-Buch to provide 100 beds all the time for patients of particular interest to research. Such an arrangement might have worked in the former East Germany, but as hospital administrators and doctors in the west see each bed as a source of income, it is unlikely to work in the united Germany.

At the same time, researchers at ZIMB were enraged to discover that Wissenschaftsrat had recommended reducing personnel there disproportionately more than at the other two institutes at Berlin-Buch.

Whereas the overall number of researchers would drop from about 1,500 to 500 or 600 if the recommendation is followed, ZIMB director Günter Pasternak calcu- lated that ZIMB might lose as many as seven-eighths of its 650 permanent staff members.

Although researchers at ZIMB had expected the council to recommend cuts affecting as much as even 50 per cent of the staff, no one was prepared for the scope of the reductions actually proposed. Institute researcher Tom Rapoport says it would be a cruel blow to reduce the staff by so much at one time, not least because the level and duration of unemployment benefits are far from certain. Wissenschaftsrat chairman Dieter Simon says that the fate of the researchers was not part of the council's agenda. "We just made structural recommendations".

Nevertheless, ZIMB researchers familiar with the text of the recommendations say that politics rather than science was the main criterion of the council. They say that while ZIMB researchers received many positive reviews, groups there did not fare as well in the recommendations as groups in the other two institutes, whose focus is much closer to the purpose of the proposed new centre.

\section{Good review for Zeuthen}

Like Berlin-Buch, the institute at Zeuthen is also considered to be one of the best that East Germany had to offer. Groups from Zeuthen participated in high-energy physics experiments at stateof-the-art research centres such as DESY (Deutsches Elektronen Synchrotron) in Hamburg and CERN in Geneva as well as on cosmic-ray projects at Lake Baikal in the Soviet Union.

Because it did not want to witness the dismantling of an institute that functions well and might play a role in raising the standards of physics in eastern Germany, the council recommended that the Zeuthen institute be preserved, and linked to DESY as some sort of satellite.

The leadership at DESY has mixed feelings about absorbing the Zeuthen institute. Although DESY's directors are happy that an institution with such a good reputation got good marks from Wissenschaftsrat, the head of the DESY research division, Paul Söding, says that it will be a "difficult question" whether the institute at Zeuthen can be absorbed.

It would be unprecedented for DESY, which builds and maintains particle accelerators, to absorb one of its users, one with virtually no equipment of its own. In addition, there is no money in the current DESY budget (financed primarily by the Bonn Research Ministry) for such an acquisition. Nevertheless, Söding says that DESY will offer any help it can to its new potential colleagues while debating its course.

Steven Dickman
Politics rears its notso-ugly head

THE Wissenschaftsrat recommendations for the future of the institutes at BerlinBuch and Zeuthen show that research quality is not the only criterion being considered in reforming German science.

As Wissenschaftsrat members assess the level of research in an eastern German institute or department, they must attempt to integrate any new structure they recommend into a densely populated network of research institutions in the west.

The following factors come into play: How easily can research be integrated into existing structures, such as universities or national laboratories (Grossforschungseinrichtungen)? Are there any institutes in the west doing this type of research? How does the institution fit in with the local research infrastructure?

A comparison of the recommendations for the institutes at Berlin-Buch and at Zeuthen (see left) shows how important these factors can be. Reading between the lines, some other reasons are apparent: although only just outside Berlin, unlike the institutes at Berlin-Buch, the Zeuthen institute is in a Land, Brandenburg, where there is virtually no basic research and no universities. Berlin, by contrast, is overflowing with research institutions.

Zeuthen was also saved by its international contacts, which extended west as well as east, and by the relatively large percentage of researchers judged to be doing high-level research.

Furthermore, because much of the work done at Zeuthen itself was theoretical, consisting of the analysis of experimental results obtained at DESY, CERN and elsewhere, the institute was not hurt as badly as others by the lack of equipment. Finally, Zeuthen profited by the sheer numbers involved: it is easier to save a majority of 220 researchers than it is to save a majority of 1,500 researchers.

Steven Dickman

\section{Simon stays}

THE science council Wissenschaftsrat, wanting a steady hand on the rudder in the difficult process of reunifying German science, has re-elected Dieter Simon for at least one more year as its chairman. Simon, may serve up to three more years in the post. He became chairman in 1989.

Normally, Simon would have had to step down not only from the chairmanship but from the council itself because his two three-year terms as a member had expired. But German President Richard von Weizsäcker, who oversees nominations to the council, urged members of the council's scientific commission to waive the six-year rule in Simon's case. The motion was approved unanimously. 